\title{
Effects of a Community-based Follow-up Program for Parents with Premature Infants on Parenting Stress, Parenting Efficacy, and Coping
}

\author{
Eun Sun $\mathrm{Ji}^{1}$, Ka Ka Shim ${ }^{2}$ \\ ${ }^{1}$ Associate Professor, Department of Nursing, KonKuk University Glocal Campus, Seoul; ${ }^{2}$ Assistant Professor, Department of Nursing, SangMyung University \\ 2Campus, Cheonan, Korea
}

Purpose: This study was conducted to evaluate the efficacy of a community-based follow-up program on parenting stress, parenting efficacy, and coping among parents with premature infants. Methods: A non-equivalent control group pre-post quasi-experimental design was used. This program consisted of structured home visits and self-help group meetings for 6 months. The experimental group $(n=29)$ received visits by an experienced neonatal intensive care unit (NICU) nurse and the control group $(\mathrm{n}=27)$ was visited by a visiting nurse. Data were analyzed using the $x^{2}$ test, $\mathrm{t}$-test, and analysis of covariance. Results: Parents' coping behavior significantly differed in the experimental group compared to the control group ( $\mathrm{t}=3.14, p=.003$ ). In particular, coping subscale I, for maintaining the family situation ( $t=2.63, p=.011)$, and subscale III, for understanding the infant's medical situation ( $\mathrm{t}=4.30, p<.001)$, showed significant differences in the experimental group. There were no significant between-group differences in parenting stress or parenting efficacy. Conclusion: The findings of this study suggest that home visits by an experienced NICU nurse provided through a community-based follow-up program were an effective intervention to improve coping behavior among parents with premature infants.

Key words: Premature infants; Follow-up studies; Parenting; Coping behavior

\section{Corresponding author Ka Ka Shim \\ https://orcid.org/0000-0003-4560-381X}

Department of Nursing, SangMyung University 2Campus,

31 Sangmyeongdae-gil, Dongnam-gu, Cheonan 31066, Korea

TEL +82-41-550-5433 FAX +82-41-550-5545

E-MAIL shimka2@smu.ac.kr

*This study was supported by KonKuk University in 2018.

Received May 31, 2020 Revised Jun 8, 2020 Accepted Jun 16, 2020 (a) This is an Open Access article distributed under the terms of the Creative Commons Attribution NonCommercial License (http://creativecommons.org/licenses/by-nc/4.0/) which permits unrestricted noncommercial use, distribution, and reproduction in any medium, provided the original work is properly cited.

\section{INTRODUCTION}

\section{Need for Study}

Follow-up programs after discharge for premature infants play an important role in promoting premature babies' health and effective parenting [1]. In Korea, follow-up programs for premature infants are centered on hospitals, and outpatient or telephone counseling is mainly conducted for mothers [2]. Currently, some state-centered health centers provide health care services through visiting nursing services or maternal health services [3]. The professional competence of a visiting nurse is very important because a visiting nurse must meet with premature babies and their parents for an extended period of time and be responsible for linkage with families in the community setting after discharge. Internationally, programs are being implemented to manage premature mothers before childbirth and after discharge through ongoing interventions, extending from the hospital to home visits after discharge $[1,4]$. It has been reported that delivering information through parent education and conducting interventions, including social support and specialist counseling, are effective ways to help parents of premature infants overcome and adapt to the 
stress that they experience [5]. Therefore, it is necessary to develop follow-up programs focused on premature infants and their parents that can continue after discharge.

Prematurity is a risk factor for the development of motor, psychiatric, behavioral, and emotional disorders in comparison with normal babies; consequently, mothers of premature infants are subject to a substantial amount of stress in the process of parenting and monitoring their children's health following discharge [6]. Parents' accumulated stress and uncertainty regarding their parenting methods diminish their confidence in their parenting skills, and they develop poor coping behaviors in the process of resolving the causes of stress and associated difficulties [7]. In premature mothers, parenting stress increases aggression and helplessness, negatively affecting the normal growth of a child $[6,8]$.

Parents are generally more likely to take better care of their children when they are capable of managing their feelings and responding to a crisis [9]. As mothers typically have the primary responsibility for both parenting and family health, coping strategies are extremely important to help mothers adjust to parenting stress and gain confidence in resolving difficult situations [10]. According to McCubbin et al. [11], responding to stressful situations by utilizing psychological, social, and material resources is helpful for appropriate stress management to allow the family to perceive stress as a positive factor and to overcome it. The transition time from the hospital to home is, in particular, the time of the greatest crisis among mothers of premature infants; therefore, follow-up programs must be provided after discharge to allow mothers of premature infants to take appropriate measures while facing struggles that include parenting stress experienced during this time.

Previous studies have presented the importance of social support and linkage with community services for premature infants, demonstrating improvements of health in premature infants, parenting stress, and family coping after providing a systematic follow-up program for mothers of premature infants $[1,10]$. Despite studies on post-discharge education in mothers of premature infants, research on community based follow-up programs is lacking.

Upon discharge from the neonatal intensive care unit (NICU), an emergency event or ongoing therapies such as oxygen administration, tube feeding, medication administration, and apnea monitoring evoke fright as the parents assume responsibility for their premature infant $[9,10]$. Therefore, community based follow-up programs are necessary to reduce the parenting stress faced by these parents and to enable them to effectively respond and adapt to such crises [8]. In contrast to hospital-centered programs, which provide home visits by a medical team, followed by treatment, in a commun- ity-based program, visiting nurses manage assessments of developmental delays, primary health care, newborn care, parenting education, and social support [2,8]. Inconsistent care during the transition from the hospital to the community can cause distress and confusion in parents of premature infants [4]. Because there is a very limited number of available neonatal nurses working in community health centers, parents of premature infants receive home care from community visiting nurses $[1,4]$. In order to develop a community-based follow-up program for premature infants, it was important to strengthen the capacity of home visiting personnel, who can participate in community programs involving parents of premature infants; therefore, a preliminary project was planned for this purpose. This study served as the basis for the development of a community-based follow-up program for parents of premature infants.

\section{Objectives}

The goal of this study was to examine whether mothers with premature infants who received a follow-up program providing tailored parenting support, including home visits by an experienced NICU nurse, had improved parenting stress, parenting efficacy, and coping compared to those who received traditional home visits.

\section{Hypotheses}

- Parenting stress would differ between the experimental group, which received home visits by an experienced NICU nurse, and the control group, which received traditional home visits.

- Parenting efficacy would differ between the experimental group, which received home visits by an experienced NICU nurse, and the control group, which received traditional home visits.

- Coping would differ between the experimental group, which received home visits by an experienced NICU nurse, and the control group, which received traditional home visits.

\section{METHODS}

\section{Study Design}

This quasi-experimental study used a nonequivalent control group pretest-posttest design to investigate the effects of home visits by an experienced NICU nurse for parents with premature infants on parenting stress, parenting efficacy, and coping. 


\section{Setting and Samples}

This study used convenience sampling to enroll mothers of premature infants who joined the infant service in S county, Seoul, South Korea. The participants in the experimental group were recruited in 2013, while the control participants were recruited in 2016. The following inclusion criteria were applied to the infants: 1) gestational age of less than 37 weeks, 2) no congenital anomalies or serious complications, and 3) corrected age of less than 6 months. Mothers were required to meet the additional following criteria: 4) having no postpartum complications, 5) being the primary caregiver of the child, and 6) understanding the purpose of the study and providing consent to participate in the study.

The sample size was calculated using the $\mathrm{G}^{*}$ Power 3.1.2 program [12] using an effect size of .08, significance level of $\alpha$ $=.05$, degree of freedom $=1$, and testability $\mathrm{oF}=0.80$, as in a preceding study [9]. This calculation indicated that 28 participants were needed for each group. Sixty participants (30 in each group) were designated in consideration of the expected dropout rate. One participant in the experimental group and three participants in the control group dropped out for reasons including relocation (two participants), change of mind (one participant), and aggravation of the child's health condition (one participant); in total, 29 participants in the experimental group and 27 participants in the control group were included in the final data analysis.

\section{Instruments}

\section{1) Parenting stress}

Parenting stress was assessed using the Parenting Stress Index (PSI), which was developed by Abidin [13] and later standardized by Chung, Lee, Park and Kim [14]. The PSI evaluates a total of 35 items divided into three categories, including 12 items concerning stress experienced by parents during parenting (parent domain), 12 items concerning dysfunctional interactions between parents and children (parent-child relationship domain), and 11 items concerning the temperamental characteristics of children (child domain). Each item is evaluated using a 5-point scale, with the score ranging from a minimum of 0 points to a maximum of 140 points. Higher scores indicate a higher level of parenting stress. For reliability, Cronbach's $\alpha$ was .91 in a study by Chung et al. [14] and was .89 in this study. The Korean version of the PSI was provided by the researcher in a standardized manner, with access available for anyone to purchase.

\section{2) Parenting efficacy}

Parenting efficacy among mothers of premature infants was assessed using the Parenting Sense of Competence (PSOC) scale, which was developed by Gibaud-Wallston [15] and modified by Shin [16]. This instrument evaluates parents' selfawareness regarding their capabilities of parenting and problem-solving. It is composed of a total of nine items evaluated using a 5-point Likert scale, in which a higher mean score indicates higher self-awareness of their parenting efficacy. Cronbach's $\alpha$ was .78 in a study by Shin [16] and was .80 in this study. Our researchers received permission to use this instrument by the researcher, who had standardized the instrument for use in Korea.

\section{3) Coping}

Coping was assessed using the Coping Health Inventory for Parents (CHIP), which was developed by McCubbin et al. [11] and modified by the researchers of this study after receiving consent for use via email. The scale evaluates a total of 45 items and is composed of 3 subscales, including 19 items on maintaining family integration, cooperation, and an optimistic definition of the situation (coping behavior subscale I); 18 items on maintaining social support, self-esteem, and psychological stability (coping behavior subscale II); and eight items on understanding the medical situation through communication with other parents and consultation with medical staff (coping behavior subscale III). Each item is evaluated using a 4-point scale ranging from 'not helpful' to 'extremely helpful,' with a higher mean score indicating better use of coping behaviors. Cronbach's $\alpha$ of the instrument at the time of development of the coping behavior subscales I, II, and III was $.77, .79$, and .71, respectively [11], and Cronbach's $\alpha$ of the subscales of the instrument in this study was .82, .75, and .69, respectively.

\section{Community-based Follow-up Program for Parents with Premature Infants}

A community-based follow-up program for parents with premature infants was developed based on the results of previous studies and a needs assessment by the parenting support center of K University Hospital [2]. Home visits and support group meetings, including special lectures and self-help meetings, were components of this program. Considering the community situation, the duration of this program was reduced to 6 months and home visits were changed to those performed by visiting nurses instead of the medical team (Table 1).

The home visit program assessed the physical, psychosocial, health behaviors, and home environment domains. For the physical domain, measurements were made of the infant's height, weight, and head circumference, and growth was checked using a growth chart. For the psychosocial domain, 
Table 1. Comparison of the Intervention Procedures of the Two Group

\begin{tabular}{|c|c|c|c|}
\hline Contents & & Experimental group & Control group \\
\hline \multirow[t]{6}{*}{ Home visiting } & Visiting members & $\begin{array}{l}\text { - One experienced NICU nurse and one visiting } \\
\text { nurse }\end{array}$ & - Two community visiting nurses \\
\hline & Number of visits & - 1 2 times per month for 6 months & - Equal to the experimental group \\
\hline & \multirow[t]{4}{*}{ Role of visitors } & $\begin{array}{l}\text { - Physical domain: } \\
\text { physical measurements, vital signs, physical } \\
\text { examinations }\end{array}$ & $\begin{array}{l}\text { - Physical domain: } \\
\text { physical measurements }\end{array}$ \\
\hline & & $\begin{array}{l}\text { - Psychosocial domain: } \\
\text { parenting attitude, affection, stress, } \\
\text { interpersonal relationships, external contact }\end{array}$ & $\begin{array}{l}\text { - Psychosocial domain: } \\
\text { same as the experimental group }\end{array}$ \\
\hline & & $\begin{array}{l}\text { - Health behavior domain: } \\
\text { nutrition, bathing, activity level, vaccinations, } \\
\text { and sleep }\end{array}$ & $\begin{array}{l}\text { - Health behavior domain: } \\
\text { same as the experimental group }\end{array}$ \\
\hline & & $\begin{array}{l}\text { - Home environment domain: } \\
\text { economic status, safety management, hygiene, } \\
\text { and degree of parenting support }\end{array}$ & $\begin{array}{l}\text { - Home environment domain: } \\
\text { same as the experimental group }\end{array}$ \\
\hline \multirow{2}{*}{$\begin{array}{l}\text { Support group } \\
\text { meetings }\end{array}$} & Number of meetings & \multicolumn{2}{|l|}{ - Once a month for 6 months } \\
\hline & Activities & \multicolumn{2}{|c|}{$\begin{array}{l}\text { - Professional education and counseling: } \\
\text { pediatricians, pediatric nursing professor, physical therapists, nutritionists, } \\
\text { psychotherapists, and special education teachers had special lectures by one person } \\
\text { each month } \\
\text { - Self-help group meeting: Q\&A between members }\end{array}$} \\
\hline
\end{tabular}

NICU=Neonatal intensive care unit; $\mathrm{Q} \& \mathrm{~A}=\mathrm{Question}$ and answer.

the home visit team evaluated the mother's parenting attitude, affection, stress, interpersonal relationships, and external contact, and the health behaviors domain included an assessment of the mother's knowledge associated with nutrition, bathing, activity level, vaccinations, and sleep in children. Additionally, the home environment domain was investigated by assessing the economic status, safety management, hygiene, and degree of parenting support; when any relevant problems were identified, education or solutions were provided.

The home visits in the experimental group were conducted by one visiting nurse and one specialized nurse with 10 years of work experience in the NICU. The experienced NICU nurse assessed the degree of developmental delay according to the child's health conditions and the corrected age by evaluating the child's vital signs, physical measurements, and physical assessment of whether any serious events were predicted. When a developmental delay or cerebral palsy was suspected, the experienced NICU nurse provided guidance on receiving the corresponding management by medical doctors and rehabilitation therapy. In contrast, the control group received home visits from two visiting nurses (community home visiting nurses), neither of whom was a specialist, and only made measurements of height, weight, and head circumference from the physical domain. The other evaluation items in the psychosocial, health behavior, and home environment domains were assessed in the same manner as the experimental group.

Both groups received home visits 1 2 times a month after a participant registered for the study, and the mean time taken in a single visit was 40 minutes. Parents for whom it was deemed necessary to conduct intensive management or who were suspected of neglect or abuse upon visiting the home were counseled in the second visit or in support group sessions. A second visits within a single month was conducted for six families; in two cases, the infant was suspected to have cerebral palsy, in two cases, the infant required oxygen therapy, and in two cases, there were concerns regarding child neglect.

Additionally, parents with premature infants in both groups participated in support group meetings that included professional education, parent counseling, and self-help sessions. In the professional education component, members of a multidisciplinary team (pediatricians, a pediatric nursing professor, physical therapists, nutritionists, psychotherapists, and special education teachers) rotated as guest speakers to provide expert knowledge. The topics of education in both the experimental and control group were the same, and all educators were the same except the nutritionists, as a nutritionist was re- 
placed for personal reasons in the control group. At the selfhelp meetings, members asked questions each other about the changes experienced by the infant during the past month and communicated about possible solutions. The support group meetings were conducted monthly in the lecture room of the $S$ district office for 2 hours each, and on average were attended by nine parents each month, with their children or alone.

\section{Data Collection and Ethical Considerations}

The experimental group data were collected after obtaining permission from K hospital in 2013 (approval no. KUH1090018) and the control group data were collected after obtaining permission of K university in 2016 (approval no. 7001355201609-HR-137), but remained unused. In 2018, research approval was approved from the Institutional Review Board of K University in Seoul (approval no. 7001355-201609-HR-137) to use the two datasets.

The data collection period of the experimental group was 6 months, beginning on April 1, 2013, when the home visit program for premature infants involving the participation of the experienced NICU nurse was initiated in S county of Seoul. Data collection for the control group began in April 1, 2016 and lasted for 6 months, while the community-based home visit program for premature infants was being operated in the same area.
After providing the subjects with an information sheet on research participation, data were collected by the researcher upon receiving voluntary written consent from the subjects, who were provided with information explaining that the data gathered would be used anonymously and would not be used for any purposes other than research, and that the subjects could withdraw consent to participation at any time during the study period.

A preliminary investigation of the experimental group was conducted using a questionnaire at the time of registration in the initial home visit program (in which the experienced NICU nurse participated) in 2013. The home visits were initiated within a month after program enrollment. Six months of monthly support group sessions followed. When the 6month period was finished, a follow-up investigation was conducted by sending a questionnaire via email or postal mail. These procedures were conducted in an identical manner for the control group in 2016. The mean time consumed in completing the questionnaire was 15 minutes, and subjects were provided with a small gift for each of two questionnaire sessions (Figure 1).

\section{Data Analysis}

The data were analyzed using SPSS for Windows version 20.0 (IBM Corp., Armonk, NY, USA). The participants' gen-

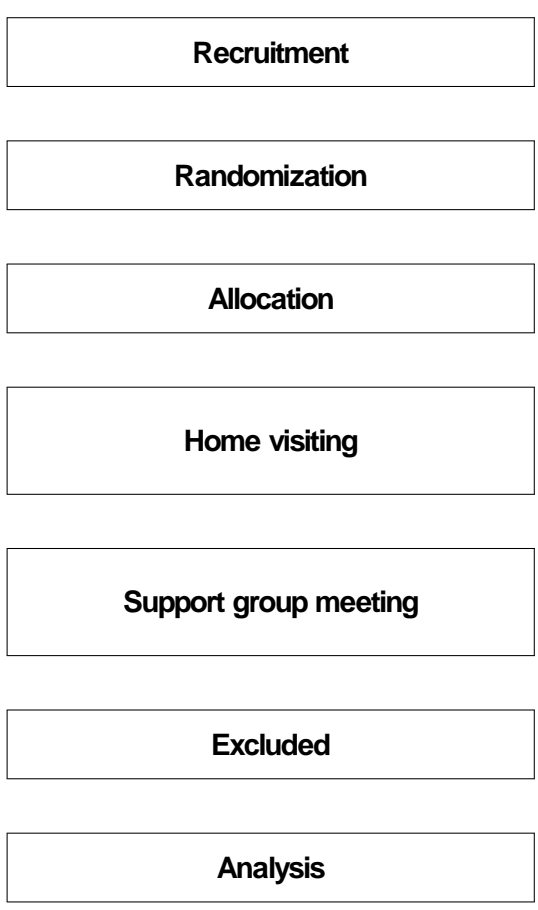

$\mathrm{NICU}=$ Neonatal intensive care unit.
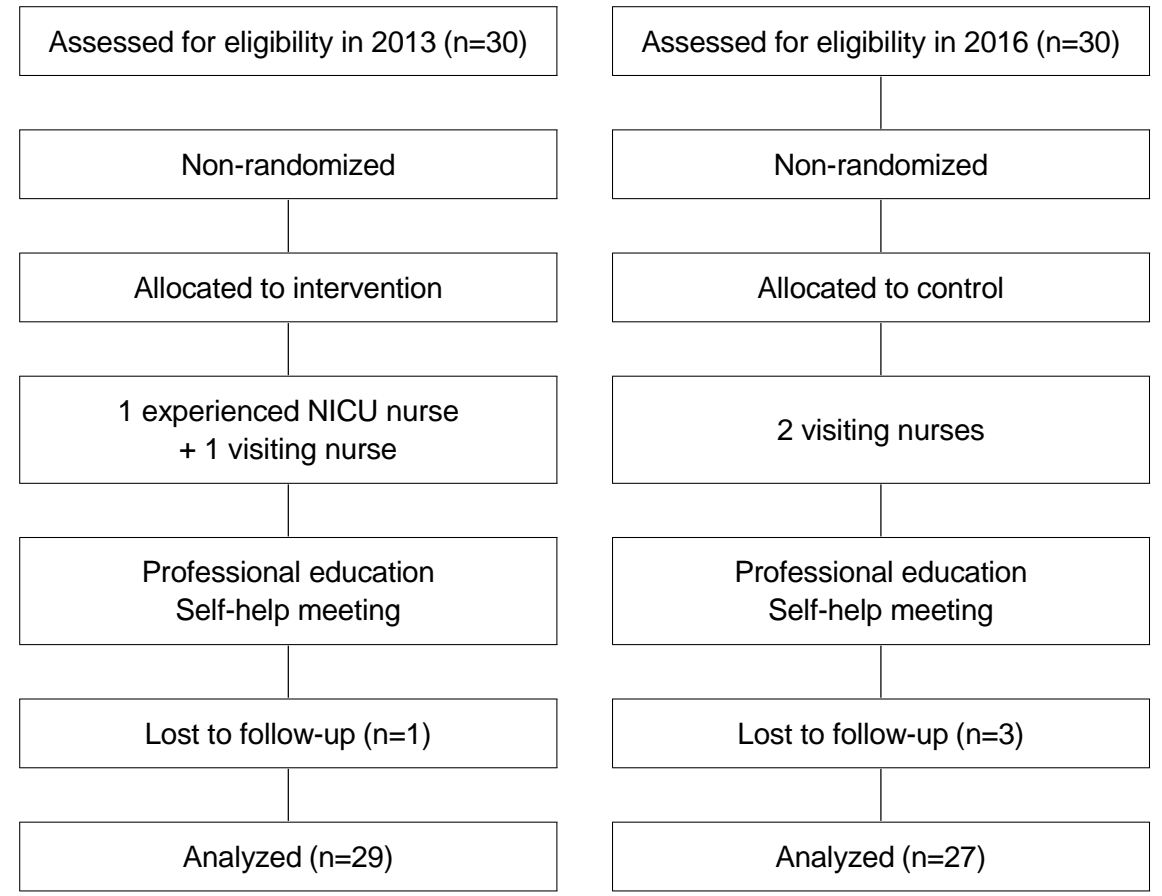

Figure 1. Flow diagram of the home visit program study. 
eral characteristics, parenting stress, parenting efficacy, and coping behaviors were analyzed using descriptive statistics, and homogeneity testing was performed using the $x^{2}$ test and the t-test. Reliability testing of the instruments used in the study to evaluate continuous variables was performed using Cronbach's $\alpha$. Differences between the two groups in the continuous variables were analyzed using the independent $t$-test. A significance level of $a=.05$ was used for all analyses.

\section{RESULTS}

\section{General Characteristics of Subjects and Homogeneity Testing}

There were 29 participants in the experimental group and 27 in the control group. In the homogeneity testing of the gen- eral characteristics of the experimental and control groups, the two groups had no significant differences in the mother's age $(\mathrm{t}=0.17, p=.861)$, education level $\left(x^{2}=1.13, p=.568\right)$, employment $\left(x^{2}=2.69, p=.100\right)$, religion $\left(x^{2}=0.11, p=.740\right)$, marital satisfaction $\left(x^{2}=4.27, p=.233\right)$, health problems $\left(x^{2}=4.42\right.$, $p=.352)$, and history of artificial insemination $\left(x^{2}=2.56, p=\right.$ .277). For the infants, homogeneity was verified for birth weight $(\mathrm{t}=0.23, p=.816)$, gestational age $(\mathrm{t}=0.65, p=.519)$, and length of hospital stay $(\mathrm{t}=0.08, p=.936)$.

The dependent variables-parenting stress $(\mathrm{t}=0.21, p=.831)$, parenting efficacy $(\mathrm{t}=0.30, p=.759)$, and coping $(\mathrm{t}=0.82, p=.411)$ -demonstrated a normal distribution according to the Kolmogorov-Smirnov test, and the t-test showed no significant differences between the two groups, demonstrating homogeneity (Table 2).

Table 2. Homogeneity of General Characteristics and Dependent Variables of Participants

$(N=56)$

\begin{tabular}{|c|c|c|c|c|c|c|c|}
\hline \multirow{2}{*}{ Variables } & \multirow{2}{*}{ Characteristics } & \multirow{2}{*}{ Categories } & \multirow{2}{*}{ Range } & \multirow{2}{*}{$\begin{array}{c}\text { Exp. }(n=29) \\
n(\%) \text { or } M \pm S D\end{array}$} & \multirow{2}{*}{$\begin{array}{c}\text { Cont. }(\mathrm{n}=27) \\
\mathrm{n}(\%) \text { or } \mathrm{M} \pm \mathrm{SD}\end{array}$} & \multirow{2}{*}{$x^{2}$ or $\mathrm{t}$} & \multirow{2}{*}{$p$} \\
\hline & & & & & & & \\
\hline \multirow{13}{*}{$\begin{array}{l}\text { Mothers' } \\
\text { characteristics }\end{array}$} & \multicolumn{3}{|l|}{ Age (year) } & $35.4 \pm 3.8$ & $35.2 \pm 4.4$ & 0.17 & .861 \\
\hline & \multirow[t]{2}{*}{ Education level } & \multirow{2}{*}{\multicolumn{2}{|c|}{$\begin{array}{l}\geq \text { College } \\
\leq \text { High school }\end{array}$}} & $4(14.8)$ & $2(7.4)$ & 1.13 & .568 \\
\hline & & & & $25(86.2)$ & $25(92.6)$ & & \\
\hline & \multirow[t]{2}{*}{ Employment } & \multirow{2}{*}{\multicolumn{2}{|c|}{$\begin{array}{l}\text { Employed } \\
\text { Unemployed }\end{array}$}} & $16(55.2)$ & $9(33.3)$ & 2.69 & .100 \\
\hline & & & & $13(44.8)$ & $18(66.7)$ & & \\
\hline & \multirow[t]{2}{*}{ Religion } & \multirow{2}{*}{\multicolumn{2}{|c|}{$\begin{array}{l}\text { Religious affiliation } \\
\text { No religious affiliation }\end{array}$}} & $12(41.4)$ & $10(37.0)$ & 0.11 & .740 \\
\hline & & & & 17 (58.6) & 17 (63.0) & & \\
\hline & \multirow{2}{*}{$\begin{array}{l}\text { Marital } \\
\text { satisfaction }\end{array}$} & \multirow{2}{*}{\multicolumn{2}{|c|}{$\begin{array}{l}\text { Satisfied } \\
\text { Dissatisfied }\end{array}$}} & $26(89.7)$ & $21(77.7)$ & 4.27 & .233 \\
\hline & & & & 3 (10.3) & $6(22.3)$ & & \\
\hline & \multirow{2}{*}{$\begin{array}{l}\text { Health } \\
\text { problems }\end{array}$} & \multirow{2}{*}{\multicolumn{2}{|c|}{$\begin{array}{l}\text { Has a disease } \\
\text { Has no disease }\end{array}$}} & $11(38.0)$ & $10(37.0)$ & 4.42 & .352 \\
\hline & & & & $28(62.0)$ & $17(63.0)$ & & \\
\hline & \multirow{2}{*}{$\begin{array}{l}\text { Artificial } \\
\text { insemination }\end{array}$} & No attempt & & $25(86.2)$ & $19(70.4)$ & 2.56 & .277 \\
\hline & & Attempt & & 4 (13.8) & 9 (29.6) & & \\
\hline \multirow{6}{*}{$\begin{array}{l}\text { Infants' } \\
\text { characteristics }\end{array}$} & \multirow{2}{*}{\multicolumn{3}{|c|}{ Birth weight (gm) }} & $1,651.8 \pm 282.8$ & $1,714.3 \pm 546.6$ & 0.23 & .816 \\
\hline & & & & $506.0 \sim 2,798.0^{*}$ & $490.0 \sim 2,700.0^{*}$ & & \\
\hline & \multirow{2}{*}{\multicolumn{3}{|c|}{ Gestational age (week) }} & $29.4 \pm 2.0$ & $31.2 \pm 2.2$ & 0.65 & .519 \\
\hline & & & & $24.2 \sim 35.8$ & $25.9 \sim 36.1$ & & \\
\hline & \multirow{2}{*}{\multicolumn{2}{|c|}{ Length of hospital stay (day) }} & & $37.1 \pm 5.1$ & $36.9 \pm 4.0$ & 0.08 & .936 \\
\hline & & & & $32.0 \sim 44.3^{*}$ & $33.2 \sim 45.0^{*}$ & & \\
\hline \multirow{6}{*}{$\begin{array}{l}\text { Dependent } \\
\text { variables }\end{array}$} & \multicolumn{2}{|l|}{ Parenting stress } & $0 \sim 140$ & $86.20 \pm 17.52$ & $87.29 \pm 20.43$ & 0.21 & .831 \\
\hline & \multicolumn{2}{|l|}{ Parenting efficacy } & $0 \sim 45$ & $30.68 \pm 5.07$ & $30.22 \pm 6.24$ & 0.30 & .759 \\
\hline & \multicolumn{2}{|l|}{ Coping } & $0 \sim 180$ & $88.41 \pm 15.93$ & $84.25 \pm 21.34$ & 0.82 & .411 \\
\hline & \multicolumn{2}{|c|}{ Coping subscale I (family) } & $0 \sim 76$ & $39.27 \pm 6.75$ & $38.59 \pm 8.71$ & 0.32 & .743 \\
\hline & \multicolumn{2}{|c|}{ Coping subscale II (social) } & $0 \sim 72$ & $34.34 \pm 7.46$ & $32.40 \pm 9.93$ & 0.82 & .411 \\
\hline & \multicolumn{2}{|c|}{ Coping subscale III (medical) } & $0 \sim 32$ & $14.79 \pm 3.75$ & $13.25 \pm 3.86$ & 1.50 & .138 \\
\hline
\end{tabular}

${ }^{*}$ Min $\sim$ Max; Cont.=Control group; Exp.=Experimental group. 


\section{Hypothesis Testing}

Regarding hypothesis 1 , the score of parenting stress was $77.27 \pm 24.24$ points after home visits in the experimental group, and $80.81 \pm 24.11$ points after home visits in the control group. The difference was not statistically significant $(t=0.54$, $p=.586)$, so hypothesis 1 was rejected.

For hypothesis 2, the score of parenting efficacy was 33.93 \pm 4.81 points after home visits in the experimental group, and $31.44 \pm 5.79$ points after home visits in the control group. The difference was not statistically significant $(t=1.75, p=.086)$, so hypothesis 2 was rejected.

Hypothesis 3 was accepted, as the score of coping behaviors was $109.37 \pm 11.81$ points in the experimental group, and 100.88 \pm 8.21 points in the control group, which was a statistically significant difference $(\mathrm{t}=3.14, p=.003)$ (Table 3$)$. The score on coping behavior subscale I (family integration) was 46.51 \pm 4.47 points after the program in the experimental group, and $43.59 \pm 3.81$ points in the control group, demonstrating a significant difference between the two groups $(t=2.63, p=.011)$. The score on coping behavior subscale II (social support and psychological stability) was $42.93 \pm 5.96$ points after the program in the experimental group, and $40.66 \pm 3.23$ points in the control group; however, this difference was not statistically significant $(\mathrm{t}=1.78, p=.082)$. The score on coping behavior subscale III (medical consultation) was $19.93 \pm 2.40$ points after the program in the experimental group, and $16.62 \pm 3.29$ points in the control group, demonstrating a significant difference between the two groups $(\mathrm{t}=4.30, p<.001)$ (Table 3).

\section{DISCUSSION}

This interventional study was conducted to evaluate the effect of a community-based follow-up program including home visits by an experienced NICU nurse for parents of premature infants on their parenting stress, parenting efficacy and coping.

The study results showed that parenting stress decreased in both groups after home visits; however, the difference was not statistically significant. Having a greater number of home visits is more effective for reducing parenting stress [4,5]. The duration of the program provided in this study was insufficient to reduce the parenting stress of the premature infants' parents. In contrast to this study, Kim and Ji [2] found the parenting stress decreased after providing hospital based follow-up care for 1 year. In that study, parents' learning needs changed and parents needed information regarding the growth and development of their premature infant [2]. Parenting stress may last for a long time depending on the health problems faced by the premature infant; therefore, continued provision of a followup program may be effective for reducing parenting stress, which might vary depending on the infant's growth process $[4,10]$. To reduce parenting stress more effectively, the discharge program for premature infants in the hospital needs to be connected to a community follow-up program and should be provided for a sufficient period of time. To help the parents adjust to their difficult task, the initial visit should occur very early after their return home, within at least the first week $[1,5]$. Nevertheless, since parents experienced a lack of understanding and difficulties throughout the developmental stages of premature infants, the provision of home visits and support group meetings in which members of a multidisciplinary team rotated as guest speakers to provide expert knowledge reduced parenting stress. Previous studies have demonstrated that parenting stress was significantly lower in a group that received community-based information support for parenting than in a group that did not [3,8]. Kilburn and Cannon [17] reported that a systematic healthcare program composed of three home visits and telephone counseling for 6 months after discharge for mothers of premature infants resulted in a decrease in stress among these subjects. A community-based follow-up program should be implemented to provide tailored support for parenting stress related to the higher-risk condition of infants and the restricted resources for developmental care.

Second, although there was no statistically significant dif-

Table 3. Post-differences in the Dependent Variables between the Two Groups

$(N=56)$

\begin{tabular}{|c|c|c|c|c|}
\hline \multirow{2}{*}{ Variables } & Exp. $(n=29)$ & Cont. $(n=27)$ & \multirow{2}{*}{$\mathrm{t}$} & \multirow{2}{*}{$p$} \\
\hline & $\mathrm{M} \pm \mathrm{SD}$ & $\mathrm{M} \pm \mathrm{SD}$ & & \\
\hline Parenting stress & $77.27 \pm 24.24$ & $80.81 \pm 24.11$ & 0.54 & .586 \\
\hline Parenting efficacy & $33.93 \pm 4.81$ & $31.44 \pm 5.79$ & 1.75 & .086 \\
\hline Coping total & $109.37 \pm 11.81$ & $100.88 \pm 8.21$ & 3.14 & .003 \\
\hline Coping subscale I (family) & $46.51 \pm 4.47$ & $43.59 \pm 3.81$ & 2.63 & .011 \\
\hline Coping subscale II (social) & $42.93 \pm 5.96$ & $40.66 \pm 3.23$ & 1.78 & .082 \\
\hline Coping subscale III (medical) & $19.93 \pm 2.40$ & $16.62 \pm 3.29$ & 4.30 & $<.001$ \\
\hline
\end{tabular}

Cont. $=$ Control group; Exp. $=$ Experimental group. 
ference between the two groups in parenting efficacy, the score increased to a greater extent in the experimental group. The quality of care of the program provided in this study was insufficient to meet the needs of the participants. Parents reported feeling more comfortable interacting with an experienced NICU nurse during home visits because the experienced nurse was a source of useful information on how to provide optimal care and cope with emergency situations in premature infants [9]. Nevertheless, these findings are consistent with the results of other studies that reported a positive effect on parenting confidence in mothers of premature infants after conducting a post-discharge education program in which information was provided before discharge and telephone counseling was also conducted $[9,18]$. A hospital-based follow-up program for premature infants showed a significant increase in parenting efficacy after home visits by a medical team and support group meetings [2]. Parents can contact to be advised the medical team when questions or concerns arise, which is in contrast with the present program. The lack of evidence-based guidelines for premature infants may lead to inconsistent care by visiting nurses [19]. These inconsistencies can distress and confuse parents. Because of the scarcity of visiting nurses who specialize in pediatric work, home visits are rarely offered unless a health care provider considers it to be vitally necessary [4]. An experienced NICU nurse can serve as the key coordinator of the follow-up program, and a community health agency must therefore develop specific guidelines and a training program to enhance the quality of care in home services for nurses making home visits for premature infants.

Third, the significantly greater increase in coping behaviors in the experimental group in comparison with the control group demonstrates the positive effects of home visits by the experienced NICU nurse on mothers' coping behaviors. These results can be interpreted as evidence that the mothers in the experimental group were capable of overcoming stressful situations and taking effective countermeasures. Brisch, Bechinger, Betzler and Heinemann [20] applied a 3-month early intervention program composed of home visits, support groups, and individual treatment for mothers of premature infants to respond to sudden emotional crises after birth. They demonstrated a greater increase in the score of coping behaviors of subjects in the experimental group than in the control group after 14 months-results consistent with the findings of the present study.

Among the results of the three coping behavior subscales, significant differences were found between the experimental group and the control group in the scores of subscale I (family integration) and subscale III (medical consultation). This result indicates that subjects frequently utilized coping behav- iors for direct resolution of problems through integrated family support and professional counseling. In other words, mothers who participated in home visits by the experienced NICU nurse were able to integrate positive cooperation by the family when checking their premature infant's health conditions and monitoring any warning signs of developmental delays. Of course, it appears that support group provided for both groups allowed the subjects to devise approaches to crisis management and to learn strategies for coping with stress from counseling specialists such as pediatricians, a pediatric nursing professor, physical therapists, nutritionists, psychotherapists, and special education teachers. The self-help meetings provided a network with other parents who were experiencing similar challenges and an environment to freely communicate thoughts and feelings. Discussion between parents allowed an exchange of valuable information and served as a place for learning.

As parents tend to use social support and avoidance as coping behaviors when their infants' health conditions are poor, establishment of self-identity through stable interpersonal relationships and social support, which alleviate stress among mothers of premature infants, facilitates successful coping responses [21]. In the US, services for children with disabilities or developmental delays are conducted from birth to age 3 by the Individual Family Service Plan, a nursing home visiting system that provides home health care for families with high-risk infants including premature infants $[18,22]$. Various forms of social support for infants are now being developed in Korea, but the delivery of community-based healthcare projects linked to premature infants remains inadequate [2]. Public healthcare policies that can provide support for optimizing the health of premature infants need to be established by sharing information and conducting case management in connection with the hospital and the community. Hospitals must provide the community administrator with information regarding the health conditions of premature infants prior to discharge; furthermore, clinical connections and collaboration with the institution responsible for the home visit program must be established in order to provide home-visit nursing care for premature infants immediately after discharge.

The findings of this study show the importance of the participation of an experienced NICU nurse in a communitybased follow-up program for parents of premature infants. These home visits enabled effective cooperation and partnership with the mothers of premature infants through the establishment of appropriate solution plans. Participation in community-visit nursing is also useful as a way to reemploy nurses with NICU experience who are no longer active in this field. Since reemployment can be difficult for inactive nurses in this position due to their job satisfaction and career history, 
community visits by experienced NICU nurses should be encouraged as a way to enhance nursing professionalism and clinical self-efficacy [23]. This study may contribute to the expansion of the role of nurses with NICU experience in the community to include not only medical nursing interventions for preterm infants, but also support for children with developmental delays and systematic management of family health promotion. Additionally, support group meetings in accordance with the educational needs of parents of premature infants facilitated ongoing improvements in parenting competencies.

Because this study analyzed a small number of participants in $S$ county, the results need to be interpreted carefully. Moreover, data were collected separately in 2013 and 2016; therefore, the exogenous variables that may have affected participants' characteristics were not controlled. The reliability score of the measurements used in this study was low; therefore, in subsequent research it will be necessary to identify and exclude the items that reduced reliability.

\section{CONCLUSION}

In accordance with the increase in the number of premature infants in Korea, specialized healthcare, information dissemination, and communication with the parents of premature infants are necessary to promote optimal growth and development among these infants upon returning home after discharge. This study was conducted to evaluate a communitybased follow-up program with home visits by an experienced NICU nurse designed to decrease parenting stress and to increase parenting efficacy and coping behaviors among mothers of premature infants. Monthly home visits and support group meetings provided professional education and counseling, as well as a framework for maintaining interactions among the members. The community-based follow-up program with home visits by an experienced NICU nurse was effective in increasing coping behaviors against stress among mothers of premature infants. In order to improve parenting stress, parenting efficacy, and coping among parents of premature infants, it is necessary to develop guidelines and provide educational programs to improve the quality of care provided by visiting nurses with responsibility for premature infants. Consequently, this study provides evidence for the need to develop and implement a community-based parenting follow-up program based on a social support system involving home visiting by specialists within the community and support group sessions for the future establishment of public healthcare support policies regarding post-discharge management of premature infants.

\section{Conflict of interest}

No existing or potential conflict of interest relevant to this article was reported.

\section{REFERENCES}

1. Orton JL, Olsen JE, Ong K, Lester R, Spittle AJ. NICU graduates: The role of the allied health team in follow-up. Pediatric Annals. 2018;47(4):e165-e171.

https://doi.org/10.3928/19382359-20180325-02

2. Kim MH, Ji ES. Effects of a hospital based follow-up program for mothers with very low birth weight infants. Journal of Korean Academy of Nursing. 2016;46(1):79-89.

https://doi.org/10.4040/jkan.2016.46.1.79

3. Lee JY, June KJ, Cho SH. Competencies of nurses in a maternal early childhood sustained home-visiting program. Journal of Korean Academy of Community Health Nursing. 2017;28(4):397-409.

https://doi.org/10.12799/jkachn.2017.28.4.397

4. Greta LL, Kathryn HA, Johanna F. Transition of premature infants from hospital to home life. Neonatal Network. 2021;31(4):207-214.

5. Meijssen DE, Wolf M, Koldewijn K, Van Wassenaer AG, Kok JH, Van Baar AL. Parenting stress in mothers after very preterm birth and the effect of the infant behavioral assessment and intervention program. Child. 2011;37(2):195-202.

https://doi.org/10.1111/j.1365-2214.2010.01119.x

6. Hwang HS, Kim HS, Yoo IY, Shin HS. Parenting stress in mothers of premature infants. Child Health Nursing Research. 2013;19(1): 39-48. https://doi.org/10.4094/chnr.2013.19.1.39

7. Im M, Oh J. Integrative review on caring education papers for parents with a premature infant. Child Health Nursing Research. 2013;19(2):120-129. https://doi.org/10.4094/chnr.2013.19.2.120

8. Avellar SA, Supplee LH. Effectiveness of home visiting in improving child health and reducing child maltreatment. Pediatrics. 2013; 132(Suppl 2):S90-S99.

https://doi.org/10.1542/peds.2013-1021G

9. Choi HS, Shin YH. Effects on maternal attachment, parenting stress, and maternal confidence of systematic information for mothers of premature infants. Child Health Nursing Research. 2013;19(3):207215. https://doi.org/10.4094/chnr.2013.19.3.207

10. Rowe J, Jones L. Discharge and beyond. A longitudinal study comparing stress and coping in parents of preterm infants. Journal of Neonatal Nursing. 2010;16(6):258-266. https://doi.org/10.1016/j.jnn.2010.07.018

11. McCubbin HI, McCubbin MA, Patterson JM, Cauble AE, Wilson LR, Warwick W. CHIP-Coping health inventory for parents: An assessment of parental coping patterns in the care of the chronically ill child. Journal of Marriage and the Family. 1983;45(2):359370. https:// doi.org/10.2307/351514

12. Faul F, Erdfelder E, Lang AG, Buchner A. G*Power3: A flexible stat- 
istical power analysis program for the social, behavioral, and biomedical sciences. Behavior Research Methods. 2007;39(2):175-191. https://doi.org/10.3758/bf03193146

13. Abidin RR. Parenting stress index: Manual (PSI). Odessa, FL: Psychological Assessment Resources; 1995. p. 1-74.

14. Chung KM, Lee KS, Park JA, Kim HJ. Validation study for the Korean version of parenting stress index (K-PSI). Korean Psychological Association Annual Conference; 2008 August 20-22; Korea Military Academy. Seoul: Korean Psychological Association; 2008. p. 558-559.

15. Gibaud-Wallston J. Development and utility of the parenting sense of competence scale. Tennessee: John F. Kennedy Center for Research on Education and Human Development; 1978. p. 1-44.

16. Shin SJ. Effects of stress, social support and efficacy on mothers' parenting behaviors [dissertation]. Seoul: Yonsei University; 1997. p. 1-109.

17. Kilburn MR, Cannon JS. Home visiting and use of infant health care: A randomized clinical trial. Pediatrics. 2017;139(1):e20161274. https://doi.org/10.1542/peds.2016-1274

18. Genevieve C, Aliyah D, Shahirose SP, Sandra MR, Abhay KL, Marilyn Y. Caring for late preterm infants: Public health nurses' experiences. BMC Nursing. 2018;17(16):1-8. https://doi.org/10.1186/s12912-018-0286-y

19. Kim JS, Shin HS. Effects of a discharge education program using on-line community for parents of premature infants. Journal of Korean Academy of Child Health Nursing. 2010;16(4):344-351. https://doi.org/10.4094/jkachn.2010.16.4.344

20. Brisch KH, Bechinger D, Betzler S, Heinemann H. Early preventive attachment-oriented psychotherapeutic intervention program with parents of a very low birthweight premature infant: Results of attachment and neurological development. Attachment and Human Development. 2003;5(2):120-135. https://doi.org/10.1080/1461673031000108504

21. Perricone G, Morales MR, De Luca F, Carollo A, Maniscalco F, Caldas Luzeiro J, et al. Coping and parental role competence of mothers of preterm infant. Minerva Pediatrica. 2014;66(3):177-186.

22. Goyal NK, Teeters A, Ammerman RT. Home visiting and outcomes of preterm infants: A systematic review. Pediatrics. 2013; 132(3):502-516. https://doi.org/10.1542/peds.2013-0077

23. Han MR, Choi-Kwon S. Effect of a refresher program for inactive nurses on nursing professionalism and nursing clinical self-efficacy. Journal of Korean Academy of Nursing Administration. 2011;17 (1):44-53. https://doi.org/10.11111/jkana.2011.17.1.44 